\title{
EXTENT AND PATTERN OF REGRESSION OF LEFT VENTRICULAR HYPERTROPHY IN PATIENTS WITH SMALL SIZE CARBOMEDICS AORTIC VALVES
}

Ruggero De Paulis, MD

Luigi Sommariva, MD

Giovanni Maria De Matteis, MD

Elisabetta Caprara, MD

Fabrizio Tomai, MD

Alfonso Penta de Peppo, MD

Patrizio Polisca, MD

Carlo Bassano, MD

Luigi Chiariello, MD
Objective: To assess the extent and pattern of regression of left ventricular hypertrophy after valve replacement for aortic stenosis, we studied 26 patients receiving either 19 or $21 \mathrm{~mm}$ CarboMedics valves (group I, 13 patients) or either 23 or 25 mm CarboMedics valves (group II, 13 patients). The studies were done before the operation and after 3 years, and results were compared with those of 10 control patients. Methods: Left ventricular end-diastolic and end-systolic diameters and volumes, ejection fraction and fractional shortening, and interventricular septum and posterior wall thickness were measured. The ratio between interventricular septum and posterior wall thickness, the ratio between left ventricular wall thickness and left ventricular chamber radius, and the left ventricular mass were then calculated. Results: At follow-up there was a significant reduction in the left ventricular mass, interventricular septum, and posterior wall thickness for both patient groups $(p<0.01)$. However, only the posterior wall thickness reached normal values; the interventricular septum and the left ventricular mass indices were still significantly greater than in the control group $(p<0.01)$. Because of the incomplete regression of interventricular septal hypertrophy, the ratio between interventricular septum and posterior wall thickness was similar between both patient groups but it was significantly higher than in control subjects $(p<0.01)$. The ratio between wall thickness and chamber radius did not decrease significantly in group II patients, in whom it remained above the control values. Conclusion: Having a bileaflet aortic prosthesis of one size larger did not seem to significantly influence the pattern and the extent of regression of left ventricular hypertrophy after an intermediate period of follow-up. (J Thorac Cardiovasc Surg 1997;113:901-9)
$R^{2}$ esidual postoperative gradients are often present after aortic valve replacement with a prosthetic valve. These gradients are progressively higher as the size of the prosthetic valve decreases. Therefore small prosthetic valves might become relatively stenotic, especially when implanted in patients with a large body surface area (BSA). The presence of a significant postoperative gradient has been thought to be responsible for adverse long-

From the Cardiac Surgery Department, Tor Vergata University of Rome, Rome, Italy.

Received for publication August 6, 1996; revisions requested Oct. 4, 1996; revisions received Nov. 1, 1996; accepted for publication Nov. 8, 1996.

Address for reprints: Ruggero De Paulis, MD, Cattedra di Cardiochirurgia, Università di Roma, Tor Vergata, European Hospital, via Portuense 700, 00149 Rome, Italy.

Copyright (C) 1997 by Mosby-Year Book, Inc.

$0022-5223 / 97 \$ 5.00+0 \quad \mathbf{1 2} / \mathbf{1} / \mathbf{7 9 1 8 3}$ term mortality and morbidity. In fact, the residual postoperative gradient might influence the extent of regression of left ventricular hypertrophy that, in turn, is responsible for a higher incidence of arrhythmias and impaired ventricular function. In this study we wanted to analyze the pattern and extent of regression of hypertrophy in a group of patients receiving small CarboMedics aortic prosthetic valves (CarboMedics, Inc., Austin, Tex.) and compare the results with those of another group receiving larger valves and with a control group.

\section{Patients and methods}

Patient population. Twenty-six ambulatory patients who had prior aortic valve replacement for severe aortic stenosis were considered. Patients selected for the study were those who had the preoperative echocardiographic evaluation at our institution, who did not have other associated valvular or coronary diseases, and who had no history of systemic hypertension. Three groups of patients 
Table I. Patient characteristics

\begin{tabular}{lccc}
\hline & Group I & Group II & Control \\
\hline Age $(\mathrm{yr})$ & $63.5 \pm 11.3$ & $61.4 \pm 9.5$ & $58.6 \pm 11.6$ \\
Sex $(\mathrm{M} / \mathrm{F})$ & $5 / 8$ & $11 / 2^{*}$ & $4 / 6$ \\
$\mathrm{BSA}\left(\mathrm{m}^{2}\right)$ & $1.67 \pm 0.1$ & $1.78 \pm 0.1$ & $1.72 \pm 0.1$ \\
EAI $\left(\mathrm{cm}^{2}\right)$ & $0.76 \pm 0.1$ & $1.04 \pm 0.1 \dagger$ & - \\
Associated AI & 1 & 2 & - \\
$\begin{array}{c}\text { Maximum gradient preop } \\
\quad(\mathrm{mm} \mathrm{Hg})\end{array}$ & $93 \pm 28$ & $91 \pm 25$ & - \\
$\begin{array}{c}\text { Maximum gradient } \\
\text { postop (mm Hg) }\end{array}$ & $35 \pm 13$ & $30 \pm 11$ & - \\
\hline
\end{tabular}

$B S A$, Body surface area; $E A I$, effective area index; $A I$, aortic insufficiency. $* p=0.044$ versus group I.

$\grave{\dagger} p=0.0001$ versus group $\mathbf{I}$.

were considered. The first group (group I) comprised 13 patients receiving either a $19 \mathrm{~mm}(n=5)$ or a $21 \mathrm{~mm}$ CarboMedics $(n=8)$ prosthetic valve. The second group (group II) comprised 13 patients who received either a 23 $\mathrm{mm}(n=10)$ or a $25 \mathrm{~mm}(n=3)$ CarboMedics prosthetic valve. The third group of 10 healthy subjects, with no heart valve disease on routine diagnostic echocardiography and no history of systemic hypertension, served as a control.

All patients were evaluated before the operation and after a mean period of $30 \pm 7$ months for group I and of $32 \pm 5$ months for group II ( $p=$ not significant). Medical ethics committee approval and informed patient consent for participation in the study were obtained in all cases.

Patient characteristics are shown in Table I. A higher number of female patients was present in the smaller valve group, consistent with the fact that women have a smaller BSA and smaller aortic root. Although the BSA was smaller in the patients in group I, it was not significantly different from that of the other two groups. As a result, when the orifice areas of the prosthesis (effective orifice area as measured in vitro and obtained from the manufacturer) were indexed for the BSA to obtain the effective area index, a significant difference from patients in group II was found. Therefore, in patients in group I a significantly higher mismatch between prosthetic valve area and BSA was found (effective area index $=0.7 \mathrm{~cm}^{2} / \mathrm{m}^{2}$, Table I). Although the majority of patients had pure aortic stenosis, a moderate degree of regurgitant volume was present in one patient in group I and in two patients in group II.

Echocardiographic measurements and calculations. At each follow-up period, M-mode, two-dimensional, and Doppler echocardiography were performed with a Hewlett-Packard series $77025 \mathrm{~A}$ echocardiograph with a 2.0 to $2.5 \mathrm{MHz}$ transducer (Hewlett-Packard, Inc., Andover, Mass). Standard apical, parasternal, and subcostal views were obtained. The following parameters were measured: left ventricular end-diastolic and end-systolic diameters and volumes; ejection fraction and fractional shortening; interventricular septum and posterior wall thickness; and maximum and mean flow velocity across the valve. Then the following parameters were calculated: (1) the ratio between interventricular septum and thickness (IVS/PW) measured at the suprapapillary level (levels above the control values were considered to represent an asymmetry in the left ventricular hypertrophy); (2) the ratio between the left ventricular wall thickness (IVS+PW) and the left ventricular chamber radius $(\mathrm{Th} / \mathrm{r})$ (levels above the control values were considered to represent a pattern of concentric hypertrophy, whereas those equal to or less than the control values were considered to represent an eccentric hypertrophy); (3) the left ventricular mass was calculated from the M-mode measurements using the formula modified by Devereux and Reicher ${ }^{1}$; (4) maximum and mean valve gradients were calculated by means of the modified Bernoulli equation. All values were indexed for the BSA. All parameters were measured and calculated independently by two expert echocardiographers. The echocardiograms were reviewed by a third investigator if the first two investigators were not in agreement.

Statistical analysis. One-factor analysis of variance was used to compare echocardiographic parameters among patient groups at each observation point. When significant differences were detected, pairwise comparisons were made by the Scheffè $F$ test. One-way analysis of variance for repeated measures was used to compare echocardiographic parameters at the time of operation and at follow-up. Comparisons of the remaining continuous or discrete variables between the two groups were performed with an unpaired Student's $t$ test or a $\chi^{2}$ test, respectively (SPSS for Windows Software, SPSS, Inc., Chicago, Ill.). Data are expressed as mean \pm 1 standard deviation, unless otherwise indicated; $p$ values $<0.05$ were considered significant.

\section{Results}

New York Heart Association (NYHA) functional class improved in all patients. At each follow-up period the majority of patients $(21 / 26,81 \%)$ were in NYHA class I, and the remaining were in class II $(19 \%)$.

Echocardiographic measurements of left ventricular diameters and volumes and assessment of left ventricular function at follow-up for groups I and II and those for the control group are shown in Table II.

Preoperatively, left ventricular dimension and function were comparable between groups I and II and similar to those of the control group. Although only the end-systolic diameters and volumes were significantly higher, in patients of group II there was a trend to more ventricular enlargement with a slightly more depressed ventricular function. However, at follow-up all values for each group were within the normal range (Table II).

Preoperatively, the left ventricular mass index was significantly greater in both groups of patients than in the control subjects (Fig. 1, Table III). Although at the postoperative study both patient groups exhibited a significant decrease in left ventricular 


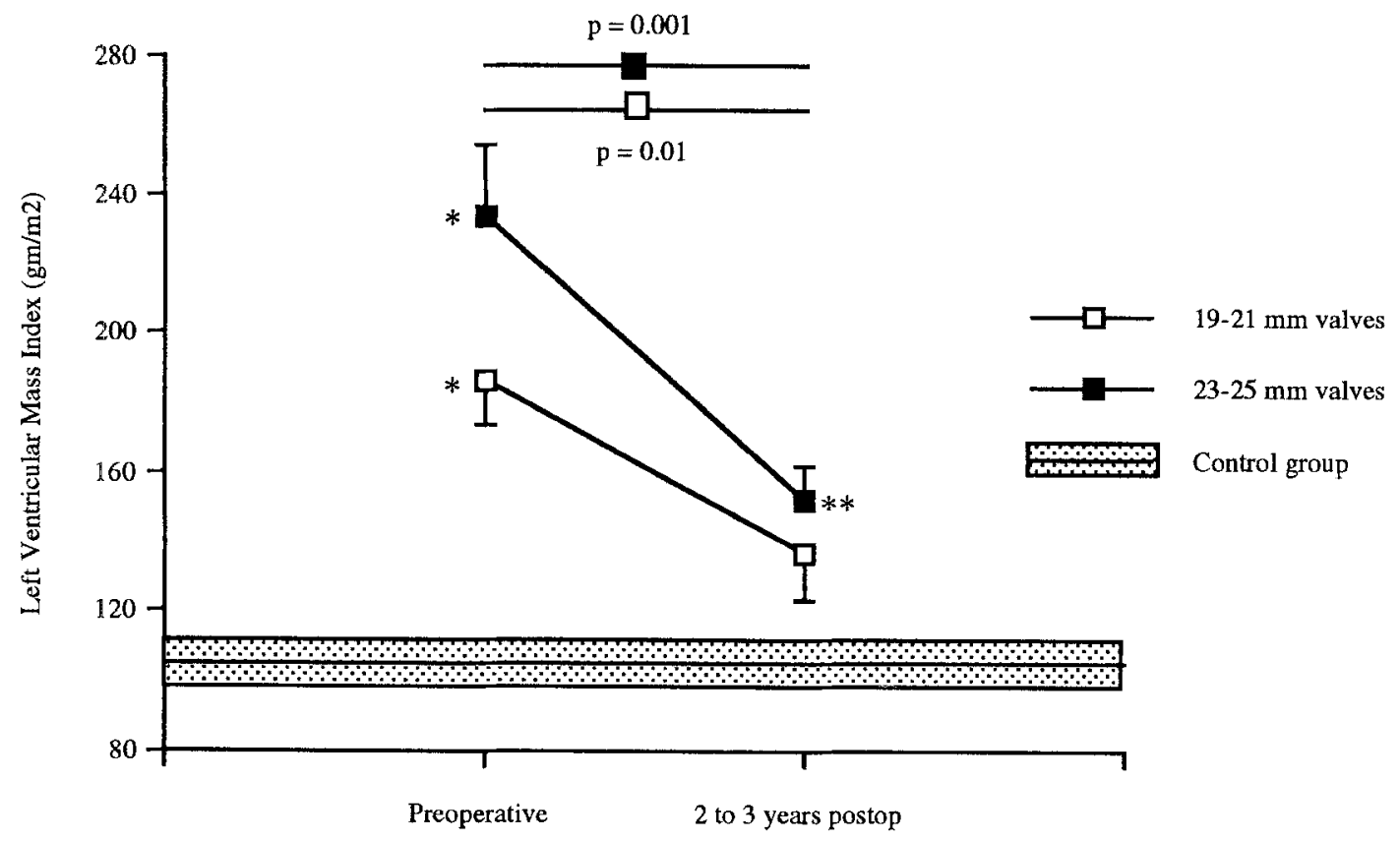

Fig. 1. Mean values ( \pm SEM) of left ventricular mass index in patients with size 19 to $21 \mathrm{~mm}$ (open square) or sizes 23 to $25 \mathrm{~mm}$ (closed square) CarboMedics aortic prostheses referenced against the control group (shaded area) at preoperative and postoperative follow-up. A significant reduction in left ventricular mass is evident for both groups of patients, although mass remained above the normal values. ${ }^{*} p=0.0001$ versus control; $* * p=0.02$ versus control.

Table II. Left ventricular diameters and volumes and left ventricular function for patients with size 19 or 21 $\mathrm{mm}$ (group I) and size 23 or $25 \mathrm{~mm}$ (group II) prosthetic aortic valves and control subjects

\begin{tabular}{|c|c|c|c|c|c|c|}
\hline & \multicolumn{6}{|c|}{ Echocardiographic parameters } \\
\hline & $\begin{array}{l}L V E D D I \\
\left(\mathrm{~mm} / \mathrm{m}^{2}\right)\end{array}$ & $\begin{array}{l}\text { LVESDI } \\
\left(\mathrm{mm} / \mathrm{m}^{2}\right)\end{array}$ & $\begin{array}{c}\text { LVEDVI } \\
\left(\mathrm{ml} / \mathrm{m}^{2}\right)\end{array}$ & $\begin{array}{c}L V E S V I \\
\left(\mathrm{ml} / \mathrm{m}^{2}\right)\end{array}$ & $\begin{array}{l}E F \\
(\%)\end{array}$ & $\begin{array}{l}F S \\
(\%)\end{array}$ \\
\hline \multicolumn{7}{|l|}{ Group I } \\
\hline Preoperative & $28 \pm 4.3$ & $17.8 \pm 2.7$ & $64.1 \pm 14$ & $20.6 \pm 8.6$ & $67 \pm 10$ & $38.5 \pm 8$ \\
\hline Follow-up & $27 \pm 5.9$ & $19.4 \pm 3.8$ & $64.7 \pm 24$ & $25.8 \pm 14.3$ & $61 \pm 10$ & $33.4 \pm 8.6$ \\
\hline \multicolumn{7}{|l|}{ Group II } \\
\hline Preoperative & $30.9 \pm 6.7$ & $20.8 \pm 4.3^{*}$ & $83.9 \pm 33$ & $35.6 \pm 19 \dagger$ & $58 \pm 10$ & $31.7 \pm 8.5$ \\
\hline Follow-up & $27.5 \pm 3.4$ & $18.4 \pm 3$ & $66 \pm 17$ & $25.9 \pm 10$ & $60 \pm 8$ & $32.7 \pm 6.1$ \\
\hline Control & $28.3 \pm 2.7$ & $18.3 \pm 1.7$ & $65.4 \pm 11$ & $23.5 \pm 7.2$ & $63 \pm 10$ & $35.3 \pm 7.4$ \\
\hline
\end{tabular}

$L V E D D I$, Left ventricular end-diastolic diameter index; $L V E S D I$, left ventricular end-systolic diameter index; $L V E D V I$, left ventricular end-diastolic volume index; LVESVI, left ventricular end-systolic volume index; $E F$, ejection fraction; $F S$, fractional shortening.

$p=0.05$ versus group $I$.

$\div p=0.02$ versus group $\mathrm{L}$.

mass, it remained significantly greater than in the control group.

The thickness of the interventricular septum and of the posterior wall, which were significantly greater before the operation in both group of patients than in the control group, decreased significantly at the postoperative study (Fig. 2, $A$ and $B$, Table III). However, whereas the posterior wall thickness was within the normal range and not significantly different from that of the control group, the interventricular septum was still significantly thicker in both patient groups than in controls. Preoperatively, the ratio of interventricular septum and posterior wall thickness (IVS/PW) in both groups was similar to that of the control group. However, because of the incomplete regression of 
Table III. Left ventricular mass index, interventricular septum, and posterior wall thickness, their ratio, and the ratio between left ventricular wall thickness to radius for patients with size 19 or $21 \mathrm{~mm}$ (group I) and size 23 or $25 \mathrm{~mm}$ (group II) prosthetic aortic valves and control subjects

\begin{tabular}{|c|c|c|c|c|c|}
\hline & \multicolumn{5}{|c|}{ Echocardiographic parameters } \\
\hline & $\begin{array}{c}\text { LV mass index } \\
\left(\mathrm{gm} / \mathrm{m}^{2}\right)\end{array}$ & $\begin{array}{c}I V S \\
(\mathrm{~mm})\end{array}$ & $\begin{array}{c}P W \\
(m m)\end{array}$ & $I V S / P W$ & $T h / r$ \\
\hline \multicolumn{6}{|l|}{ Group I } \\
\hline Preoperative & $186 \pm 45$ & $14.4 \pm 2.1$ & $12.7 \pm 2.1$ & $1.15 \pm 0.2$ & $0.56 \pm 0.08$ \\
\hline Follow-up & $136 \pm 47$ & $12.3 \pm 1.8$ & $9.8 \pm 1.5$ & $1.26 \pm 0.2$ & $0.45 \pm 0.09$ \\
\hline \multicolumn{6}{|l|}{ Group II } \\
\hline Preoperative & $234 \pm 72$ & $15.4 \pm 3.4$ & $12.7 \pm 2.3$ & $1.23 \pm 0.3$ & $0.53 \pm 0.16$ \\
\hline Follow-up & $152 \pm 35$ & $13.1 \pm 1.7$ & $10.5 \pm 1.7$ & $1.27 \pm 0.2$ & $0.48 \pm 0.1$ \\
\hline Control & $105 \pm 18$ & $9.3 \pm 1.1$ & $9 \pm 1.1$ & $1.04 \pm 0.1$ & $0.37 \pm 0.05$ \\
\hline
\end{tabular}

$L V$, Left ventricular; $I V S$, interventricular septura; $P W$, posterior wall; $T h / r$, ratio between left ventricular thickness to radius $(p$ values are indicated in Figs. 1 to 4$)$.

the interventricular septum hypertrophy and the complete regression of the posterior wall hypertrophy, at follow-up their ratio was significantly higher in both valve groups than in control subjects (Fig. 3, Table III).

Preoperatively, the ratio of left ventricular wall thickness to radius (Th/r) was significantly higher in both groups of patients than in the control group. In group I it decreased over time, and at the follow-up it was within the control values and significantly different from the preoperative values (Fig. 4, Table III). In group II the postoperative ratio of left ventricular wall thickness to radius $(\mathrm{Th} / \mathrm{r})$ did not decrease significantly, and therefore at the postoperative study it was still significantly higher than in the control group. (This result was due to an earlier and complete normalization of ventricular volumes, which were slightly larger than in group I, compared with the slower and incomplete regression of the septal thickness.)

For patients in group I who had been evaluated for another study protocol, a shorter follow-up (10.4 \pm 6.2 months) was also available, and no significant differences for all parameters considered could be detected between the two follow-up periods.

\section{Discussion}

The development of concentric hypertrophy in patients with aortic stenosis or systemic hypertension is an appropriate adaptation of the left ventricular muscle to the increase in the intracavitary pressure, ${ }^{2}$ which allows it to maintain a normal relation between systolic wall stress and ejection fraction. However, in hypertensive patients the presence of concentric hypertrophy is associated with increased morbidity and mortality. ${ }^{3,4}$ Similarly, in patients with aortic stenosis, it has been found associated with increased postoperative mortality after aortic valve replacement. ${ }^{5}$ These findings were related to several mechanisms, including a suboptimal myocardial protection of the hypertrophied heart, an abnormality in coronary flow reserve, and an exacerbation of diastolic dysfunction. Besides the increased perioperative mortality and morbidity associated with marked concentric ventricular hypertrophy, it is possible that the lack of regression of left ventricular hypertrophy after aortic valve replacement might negatively influence the long-term prognosis of this subset of patients. In the majority of cases, implantation of an aortic valve prosthesis corrects the abnormal hemodynamic burden and causes a regression of the left ventricular hypertrophy. However, the use of small aortic valve prostheses and therefore the possibility of a patient-prosthesis mismatch raises the concern that the regression of hypertrophy and the remodeling of the left ventricular geometry might not take place.

This assumption is often based on the evidence that residual postoperative gradients are often found after aortic valve replacement with small prosthetic valves. These gradients are more marked with the use of porcine valves or with the first generation of mechanical valves. In the late seventies, several authors recommended that 19 or $21 \mathrm{~mm}$ porcine valves ${ }^{6,7}$ not be used in adults because they could cause severe transprosthetic gradients, especially during exercise. ${ }^{8}$ Many different anulus-enlarging procedures ${ }^{9,10}$ have been recommended to allow the implantation of larger prostheses. The use of the tilting disc mechanical valve greatly decreased the rest and exercise gradients, so that the long-term 

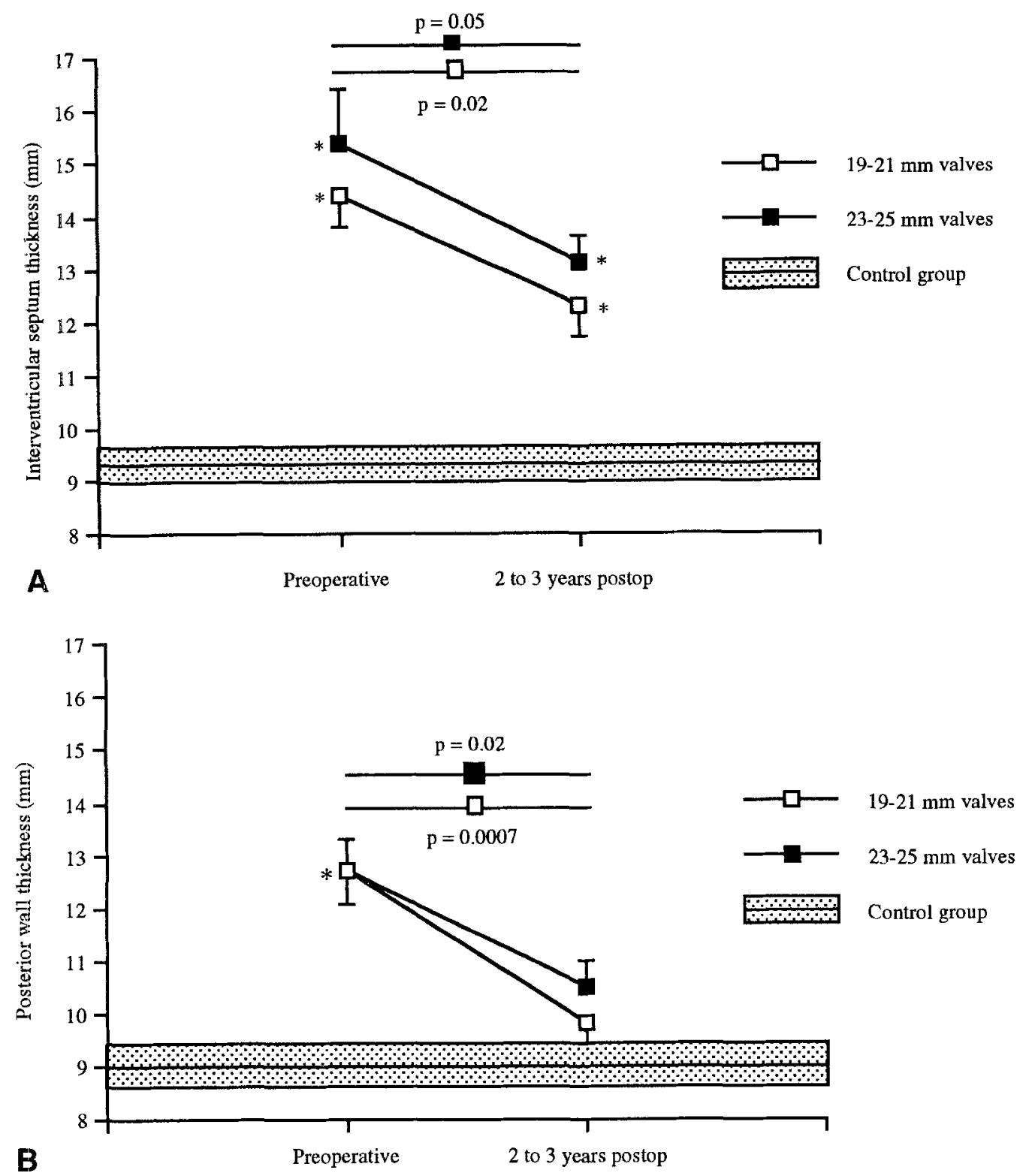

Fig. 2. Mean values ( \pm SEM) of interventricular septum (A) and left ventricular posterior wall (B) thickness in patients with size 19 to $21 \mathrm{~mm}$ (open square) or sizes 23 to $25 \mathrm{~mm}$ (closed square) CarboMedics aortic prostheses referenced against the control group (shaded area) at preoperative and postoperative follow-up. A significant reduction in interventricular septum and posterior wall thickness is evident for both groups of patients. However, at follow-up, whereas the posterior wall was within the normal range, the interventricular septum remained significantly thicker than control values for both patient groups. ${ }^{*} p=$ 0.0001 versus controls.

survival and clinical status reportedly has been unaffected by the use of small prosthesis sizes. ${ }^{11}$ However, some authors ${ }^{12}$ still found unsatisfactory the hemodynamic performances of $19 \mathrm{~mm}$ tilting disc valves.

The advent of bileaflet valves with their improved hemodynamic performances has somehow overcome the disadvantages of using small valves. Most studies evaluating the St. Jude Medical mechanical valve (St. Jude Medical, Inc., St. Paul, Minn.) reported catheterization mean gradients varying from 7 to $14 \mathrm{~mm} \mathrm{Hg}$ for the $19 \mathrm{~mm}$ valve, ${ }^{13,14}$ and similar 


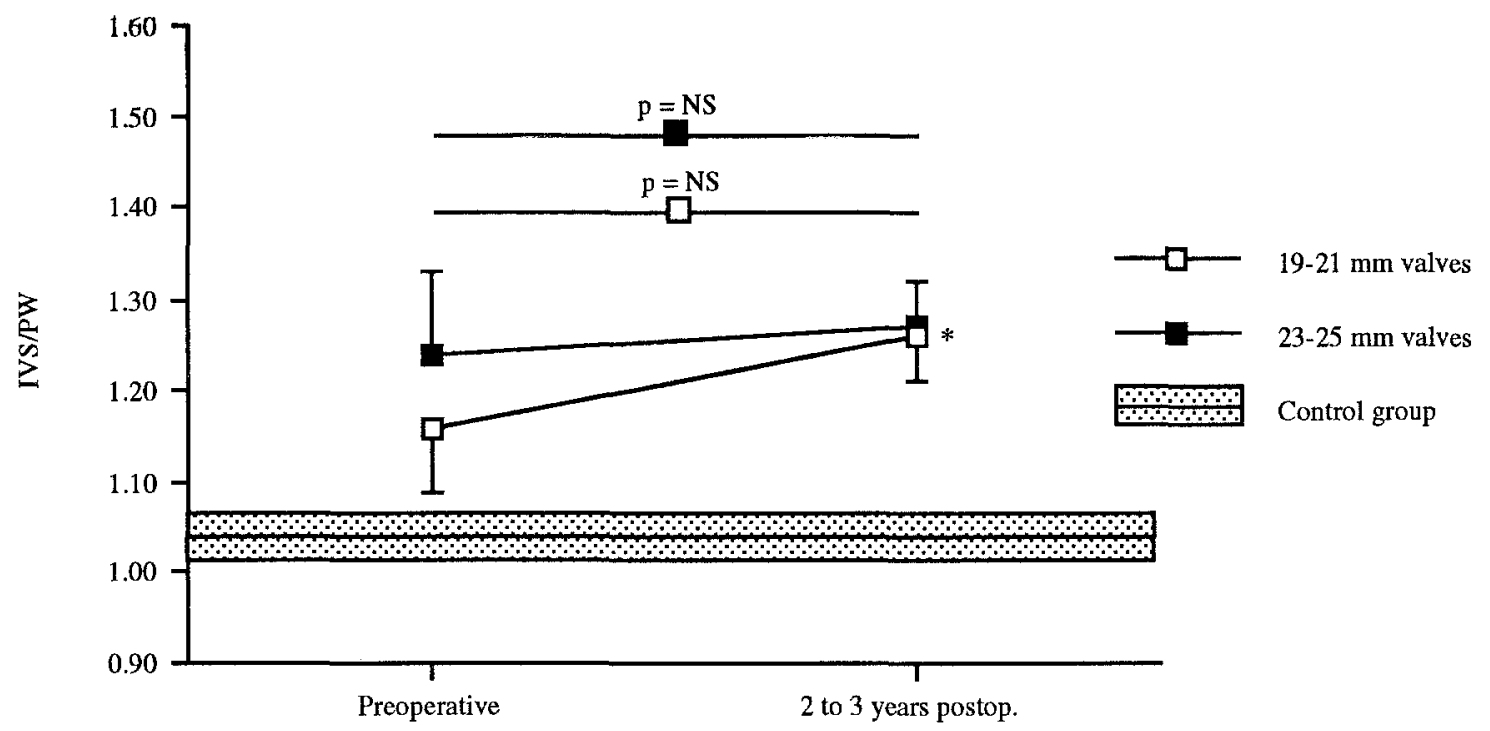

Fig. 3. Mean values $( \pm$ SEM) of interventricular septum to left ventricular posterior wall thickness ratio (IVS/PW) in patients with size 19 to $21 \mathrm{~mm}$ (open square) or sizes 23 to $25 \mathrm{~mm}$ (closed square) CarboMedics aortic prostheses referenced against the control group (shaded area) at preoperative and postoperative follow-up. Both groups of patients showed a tendency with time toward an asymmetry of their left ventricular hypertrophy. ${ }^{*} p=0.005$ versus controls; $N S$, not significant.

values were also found on the catheterization-derived gradients for the CarboMedics valve. ${ }^{15}$ However, most of the time the Doppler-derived gradients are used to evaluate and to compare different valve prostheses. We recently found postoperative Doppler gradients for small CarboMedics valves in the range of $35 \mathrm{~mm} \mathrm{Hg}$ after exercise. ${ }^{16}$ Similarly, Doppler-derived gradients for the $21 \mathrm{~mm}$ St. Jude Medical and CarboMedics valves in the range of 7 $\mathrm{mm} \mathrm{Hg}$ at rest and $24 \mathrm{~mm} \mathrm{Hg}$ after dobutamine stress echocardiography have been reported. ${ }^{17} \mathrm{Al}-$ though a good correlation between catheter-derived and Doppler-derived gradients has been reported, ${ }^{18,19}$ it is widely known that Doppler-defined gradients in bileaflet valves are often overestimated by comparison with catheter-derived gradients. ${ }^{20}$ This is due to the presence of high localized gradients and to the phenomenon of pressure recovery distal to the aortic prosthesis. Another source of error in the Dopplerderived gradients might also derive from their dependence on the opening angle of the valve. In case of valve malfunction with restricted leaflet movements, the increase of Doppler-derived gradients has been found to be considerably smaller than the increase in catheter-derived gradients. ${ }^{21}$ Considering that a prosthesis evaluation based solely on the measurement of residual Doppler-derived gradient might not be satisfactory, we thought that a more accurate evaluation of small aortic prostheses should be based on the close observation of the extent, pattern, and rate of regression of left ventricular hypertrophy. Monrad and associates $^{22}$ followed the regression of hypertrophy at an intermediate (1.6 years) and a late (8 years) period after aortic valve replacement with different valve prostheses. They noted that the regression of hypertrophy was conspicuous after surgery by the time of the intermediate study but continued at a slower rate thereafter. They concluded that the improvements occurring at a slight but constant afterload excess for the presence of the valve prosthesis indicates that the hypertrophied myocardium is operating at a reduced level. However, even late after aortic valve replacement, a moderate degree of hypertrophy was still present. Our study demonstrated that, within certain limits, there is no difference in the extent and pattern of regression of left ventricular hypertrophy in patients with different mismatches between valve prosthesis and BSA. Although after 3 years of follow-up a normalization of the myocardial mass was not obtained, a significant regression of left ventricular hypertrophy was present in all patients. The lack of normalization of myocardial mass was mainly due to the incomplete regression of the hypertrophy of the interventricular septum. It is known that in the interventricular septum there is a higher fibrous reaction and the fibrous content takes longer to decrease 


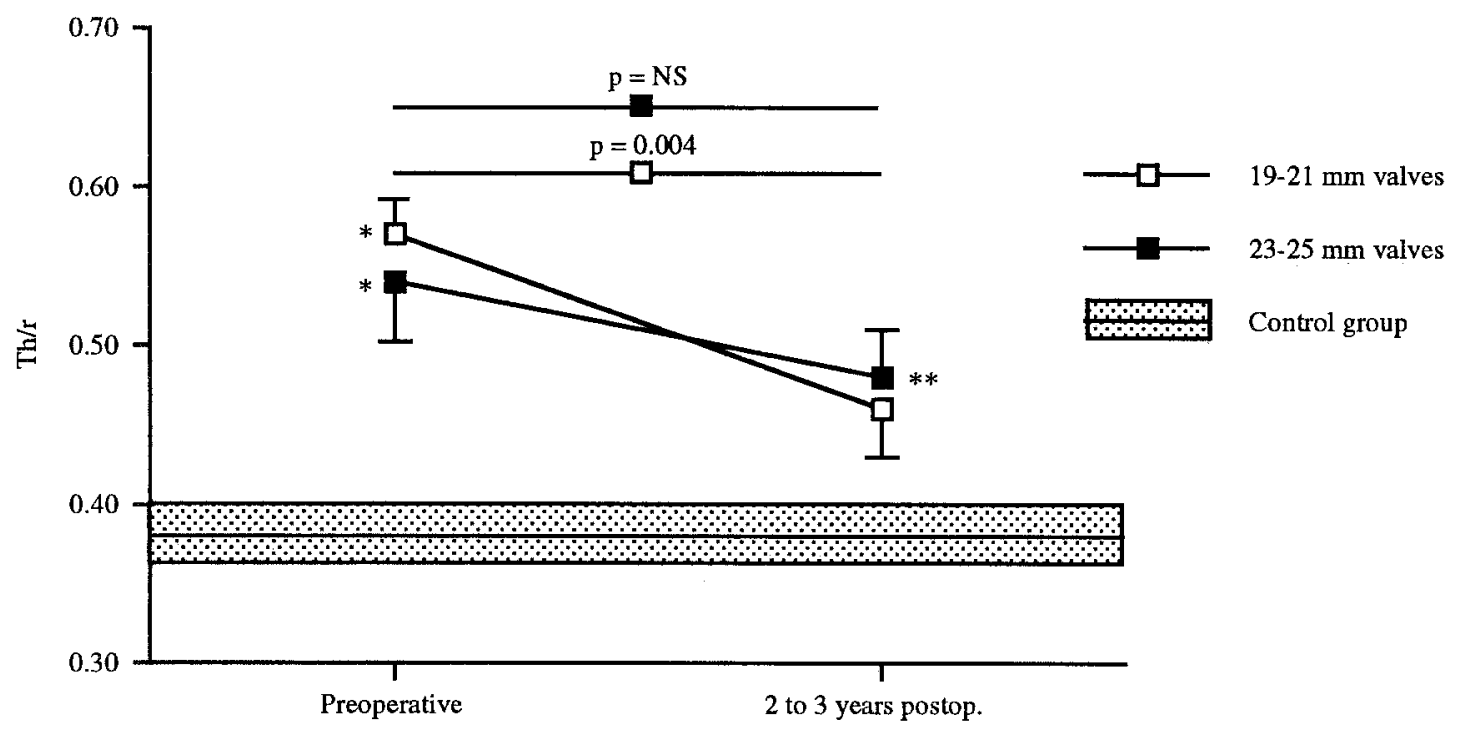

Fig. 4. Mean values ( \pm SEM) of left ventricular wall thickness/chamber radius ratio $(T h / r)$ in patients with size 19 to $21 \mathrm{~mm}$ (open square) or sizes 23 to $25 \mathrm{~mm}$ (closed square) CarboMedics aortic prostheses referenced against the control group (shaded area) at preoperative and postoperative follow-up. Both groups of patients showed a reduction with time in the pattern of concentric hypertrophy. In the larger size-prosthesis group, the hypertrophy remained significantly higher than in the control subjects because the magnitude of decrease in left ventricular diameters and volumes was greater than in the other patient group (Table II). See text for details. ${ }^{*} p=0.0009$ versus controls; ${ }^{*} p=0.02$ versus controls.

significantly. ${ }^{23}$ Nonetheless, the same results were found for patients with effective area indexes varying from 0.7 to $1 \mathrm{~cm}^{2} / \mathrm{m}^{2}$. Therefore it is possible that for the bileaflet valve the minimum requirement of 0.9 $\mathrm{cm}^{2} / \mathrm{m}^{2}$ previously suggested and based on reports $\mathrm{s}^{24,25}$ evaluating different types of bioprostheses or firstgeneration mechanical valves could be safely lowered.

Grouping together all valves and correlating the effective area index with the interventricular septum thickness and with the left ventricular mass, we were unable to find a point at which effective area index of the prosthesis was too small to negatively influence the regression of left ventricular hypertrophy $(r=0.42, p=0.03)$. Therefore this study shows that even patients with an effective area index as low as $0.7 \mathrm{~cm}^{2} / \mathrm{m}^{2}$ were able to obtain a satisfactory regression of left ventricular hypertrophy. Although an effective orifice area between 0.6 and $0.75 \mathrm{~cm}^{2} / \mathrm{m}^{2}$ is considered a severe aortic stenosis for a natural valve, it might still significantly decrease the left ventricular hypertrophy when it is related to a bileaflet prosthetic valve with optimized flow hemodynamics.

Although a larger valve prosthesis yields better hemodynamic performances, from a clinical point of view it is difficult to demonstrate a significantly worse result in the majority of patients with small valve prostheses. In a group of patients with small St. Jude Medical valves after 12 years of follow-up, Kratz and associates ${ }^{26}$ reported that having a small valve was not predictive of persistent congestive heart failure or late death. A small increase in the risk of sudden death was found only in patients with a BSA of more than $1.9 \mathrm{~m}^{2}$ receiving a $19 \mathrm{~mm}$ prosthesis. Similarly, in a large group of patients followed up for 18 years, who received different kinds of valves smaller than $21 \mathrm{~mm}$, He and associates $^{27}$ found that a mismatch between BSA and prosthesis size is a negative determinant for longterm survival only in patients with concomitant coronary artery bypass grafting. Previously, Foster and coworkers, ${ }^{11}$ evaluating 17 and $19 \mathrm{~mm}$ BjörkShiley valve prostheses, found that $93 \%$ of the patients with resting gradients higher than $30 \mathrm{~mm}$ $\mathrm{Hg}$ were in NYHA class I and concluded that resting hemodynamic studies have a limited predictive value for long-term prognosis. It is therefore evident that information on the extent of regression of left ventricular hypertrophy might be more valuable for the surgeon dealing with a small aortic anulus.

In a recent review article, Barner and colleagues ${ }^{28}$ stated that after a 6-month observation period pa- 
tients with small mechanical valves had lower reduction in left ventricular mass index, decreased exercise tolerance, and higher functional class than patients with larger valves. In particular, they found that valve size was an independent determinant (although with a weak correlation, $r=0.26$ ) of functional class. The difference from our study could be due either to the different follow-up period or to a different surgical timing.

A difference in the regression of left ventricular hypertrophy after aortic valve replacement for aortic stenosis has also been noted in patients with preoperative depressed ventricular function. ${ }^{29} \mathrm{Al}-$ though our group II patients had slightly enlarged ventricles, their ventricular function was normal and we could not include this variable in the analysis. Finally, Sim and associates ${ }^{30}$ analyzed the influence of prosthesis size on the change in left ventricular mass and concluded that $19 \mathrm{~mm}$ valves might not provide comparable reduction in left ventricular mass after aortic valve replacement. However, in their study, although the magnitude of reduction in left ventricular mass was greater in patients with valve size $21 \mathrm{~mm}$ or larger, it did not reach statistical significance. More important, all groups approached similar values in the postoperative measurements of left ventricular mass index. These findings seem to indicate that, although patients with different valve sizes might have a different rate of reduction in left ventricular hypertrophy, all patients obtain a regression of left ventricular hypertrophy to a certain point, after which it continues at a much slower rate. ${ }^{22}$ Although the numbers might be too small for meaningful conclusions, also when we compared patients with 19 mm valves $(n=5)$ and those with 21 mm valves $(n=8)$ (which combined in group I), we did not find any significant difference in all parameters considered.

The lack of substantial differences observed between our two groups of patients, even in the extent and pattern of regression of ventricular hypertrophy, testifies to the overall good performances of small bileaflet valves and confirms that in the presence of a postoperative residual gradient a longer time is probably needed for a more complete regression of left ventricular hypertrophy.

\section{Conclusions}

It seems intuitive that a more complete relief of obstruction is obtained with the implantation of a larger valve prosthesis. Therefore, especially in the small aortic root, surgeons usually attempt to im- plant the largest possible valve. However, this study suggests that in most patients the possibility and the ability to implant a prosthesis one size larger might not be justified by a significant difference, not only in the clinical status but also in the pattern and extent of regression of ventricular hypertrophy. Therefore the risk associated with an anulus-enlarging procedure or with the use of improved versions of currently available bileaflet valves, whose results are still uninvestigated, should be weighed against the trivial differences in the postoperative clinical status and the extent of regression of left ventricular hypertrophy. The new Hemodynamic Plus St. Jude Medical valve (St. Jude Medical HP) that has the same orifice as the next larger standard valve and the supraanular version of the CarboMedics valve (Top-hat) should demonstrate the same valve-related complications as the standard version before their use will be widespread.

Given the fact that in most cases the size of the prosthesis for aortic valve replacement is correlated to the body size of the patient, there are very few cases in which the mismatch between valve prosthesis and BSA seems to be significant to the point that a prosthesis of one size larger might influence the regression of left ventricular hypertrophy.

\section{Study limitations}

A limitation of this study is that the rate of regression at a longer follow-up was not analyzed. It is possible that in patients with larger valve prostheses the regression of hypertrophy will continue many years after the operation, as demonstrated by Monrad, ${ }^{22}$ Krayenbuehl, ${ }^{23}$ and their associates, whereas in the smaller valve group it might not take place. A longer follow-up period is required to unveil this aspect. Furthermore, we did not analyze the differences in the rate of regression between the two group within the first year. However, if these differences did exist, they would require monthly echocardiographic studies within the year and they would probably not have clinical relevance. Finally, the small group of patients considered might account for a less accurate statistical validation of the results. However, the patient selection needed to be very accurate, because the patients were categorized not only according to valve type and size, but also according to the absence of significant valve regurgitation, the absence of hypertension, and other cardiac abnormalities or procedures. Nonetheless, the evaluation of this small group of patients allowed us to conclude that bileaflet valves might offer 
good hemodynamic performance to the point that in a large number of cases a small difference in prosthesis size not only is not clinically relevant, but might not significantly influence the regression of left ventricular hypertrophy.

We thank A. Parma, MD, MSc, for his assistance in the statistical analysis of our data.

\section{REFERENCES}

1. Devereux RB, Reicher N. Echocardiographic determination of left ventricular mass in man. Circulation 1977;55:614-8.

2. Gaasch WH. Left ventricular radius to wall thickness ratio. Am J Cardiol 1979;43:1189-94.

3. Levy D, Garrison RJ, Savage DD, Cannel WB, Castelli WP. Prognostic implication of echocardiographically determined left ventricular mass in the Framingham heart study. N Engl J Med 1990;322:1561-6.

4. Koren MJ, Devereux RB, Casale PN, Savage DD, Laragh JH. Relation of left ventricular mass and geometry to morbidity and mortality in uncomplicated essential hypertension. Ann Intern Med 1991;114:345-52.

5. Orsinelli DA, Aurigemma GP, Battista S, Krendell S, Gaasch WH. Left ventricular hypertrophy and mortality after aortic valve replacement for aortic stenosis: a high risk subgroup identified by preoperative relative wall thickness. J Am Coll Cardiol 1993;22:1679-83.

6. Cohn LH, Sanders JH Jr, Collins JJ Jr. Aortic valve replacement with the Hancock porcine xenograft. Ann Thorac Surg 1976:22:221-7.

7. Jones EL, Craver JM, Morris DC, et al. Hemodynamic and clinical evaluation of the Hancock xenograft bioprosthesis for aortic valve replacement (with emphasis on the management of the small aortic root). J Thorac Cardiovasc Surg 1978;75: 300-8.

8. Hannah H, Reis RL. Current status of porcine heterograft prostheses: a 5 year appraisal. Circulation 1975;52(Suppl): II30-6.

9. Manouguian S, Seybold-Epting W. Patch enlargement of the aortic valve by extending the aortic incision into the anterior mitral leaflet. J Thorac Cardiovasc Surg 1979;78:402-8.

10. Konno S, Imai Y, Nakajima M, Tetsuno K. A new method for prosthetic valve replacement in congenital aortic stenosis associated with hypoplasia of the aortic valve ring. J Thorac Cardiovasc Surg 1976;70:920-7.

11. Foster AH, Tracy CM, Greenberg GJ, McIntosh CL, Clark RE. Valve replacement in narrow aortic roots: serial hemodynamics and long-term clinical outcome. Ann Thorac Surg 1986;42:506-16.

12. Schaff HV, Borkon AM, Hughes $C$, et al. Clinical and hemodynamic evaluation of the $19 \mathrm{~mm}$ Björk-Shiley aortic valve prosthesis. Ann Thorac Surg 1981;32:50-7.

13. Gray RJ, Chaux A, Matloff JM, et al. Bileaflet, tilting disc and porcine aortic valve substitutes: in vivo hydrodynamics characteristics. J Am Coll Cardiol 1984;3:321-7.

14. Chaux A, Gray RJ, Matloff JM, Feldman H, Sustaita H. An appreciation of the new St. Jude valvular prosthesis. J Thorac Cardiovasc Surg 1981;81:202-11.
15. Ihlen H, Molstad P, Simonsen S, et al. Hemodynamic evaluation of the CarboMedics prosthetic heart valve in the aortic position: comparison of noninvasive and invasive techniques. Am Heart J 1992;123:151-9.

16. De Paulis R, Sommariva L, Russo F, Tomai F, Tondo A, Pagliaricci C, et al. Doppler echocardiography evaluation of the CarboMedics valve in patients with small aortic anulus and valve prosthesis-body surface area mismatch. J Thorac Cardiovasc Surg 1994;108:57-62.

17. Izzat MB, Birdi I, Wilde P, Bryan AJ, Angelini GD. Comparison of hemodynamic performances of St. Jude Medical and CarboMedics $21 \mathrm{~mm}$ aortic prostheses by means of dobutamine stress echocardiography. J Thorac Cardiovasc Surg 1996;111:408-15.

18. Sager KB, Wann LS, Paulsen WHJ, Romhilt DW. Doppler echocardiographic evaluation of Hancock and Björk-Shiley prosthetic valves. J Am Coll Cardiol 1986;7:681-7.

19. Burstow DJ, Nishimura RA, Bailey KR, et al. Continuous wave Doppler echocardiographic measurements of prosthetic valve gradients: a simultaneous Doppler-catheter study. Circulation 1989;80:504-14.

20. Baumgartner $\mathrm{H}$, Khan S, DeRobertis M, Czer L; Maurer G. Effect of prosthetic aortic valve design on the Dopplercatheter gradient correlation: an in vitro study of normal St. Jude, Medtronic-Hall, Starr-Edwards and Hancock valves. J Am Coll Cardiol 1992;19:324-32.

21. Baumgartner $H$, Shima $H$, Kuhn P. Effect of prosthetic valve malfunction on the Doppler-catheter gradient relation for bileaflet aortic valve prostheses. Circulation 1993;87:1320-7.

22. Monrad ES, Hess OM, Murakami T, Nonogi H, Corin WJ, Krayenbuehl HP. Time course of regression of left ventricular hypertrophy after aortic valve replacement. Circulation 1988;77:1345-55.

23. Krayenbuehl HP, Hess OM, Monrad ES, Schneider J, Mall G, Turina M. Left ventricular myocardial structure in aortic valve disease before, intermediate, and late after aortic valve replacement. Circulation 1989;79:744-55.

24. Rahimtoola SH. The problem of valve prosthesis-patient mismatch. Circulation 1978;58:20-4.

25. Dumesnil JG, Honos GN, Lemieux M, Beauchemin J. Validation and application of indexed aortic prosthetic valve areas calculated by Doppler echocardiography. J Am Coll Cardiol 1990;16:637-43.

26. Kratz JM, Sade RM, Crawford FA, Crumbley AJ III, Stroud MR. The risk of small St. Jude valve prostheses. Ann Thorac Surg 1994;57:1114-9.

27. He GW, Grunkemeier GL, Gately HL, Furnary AP, Starr A. Up to thirty-year survival after aortic valve replacement in the small aortic root. Ann Thorac Surg 1995;59:1056-62.

28. Barner HB, Labovitz AJ, Fiore AC. Prosthetic valves for the small aortic root. J Card Surg 1994;9:154-7.

29. Uwabe K, Kitamura M, Hachida M, Endo M, Hashimoto A, Koyanagi $\mathrm{H}$. Long term outcome of left ventricular dysfunction after surgery for severe aortic stenosis. J Heart Valve Dis $1995 ; 4: 503-8$.

30. Sim EKW, Orszulak TA, Schaff HV, Shub C. Influence of prosthesis size on change in left ventricular mass following aortic valve replacement. Eur J Cardiothorac Surg 1994;8: 293-7. 